\title{
TOWARD A REALIZATION OF PSYCHOLINGUISTIC PRINCIPLES IN THE ESL READING CLASS ${ }^{1}$
}

\author{
Mark A. Clarke and Sandra Silberstein ${ }^{2}$ \\ English Language Institute \\ University of Michigan
}

\begin{abstract}
This article is an attempt to utilize psycholinguistic research to develop a framework for the teaching of reading to second language (L2) learners. The first section highlights current psycholinguistic reading theory and develops goals for $\mathrm{L} 2$ reading teachers based on this theory. The proficient reader is viewed as an active, information-processing individual who uses a minimum number of clues to extract the author's message from the page. It becomes the responsibility of teachers to train students to determine their own goals and strategies for a particular reading, to give students practice and encouragement in using a minimum number of syntactic and semantic clues to obtain the maximum amount of information, and to encourage students to take risks, to guess, and to ignore their impulses to be always correct. In an attempt to translate theory into practice, the second section of the article explores the implications of a psycholinguistic perspective for the learning environment, teacher behavior, and the preparation and use of L2 reading materials. The optimum learning environment is viewed as one in which students and teachers work together: teacher intervention is minimized as students are encouraged to use their developing skills to solve reading problems on their own. Materials development is viewed as being composed of the development of reading skills exercises (scanning, skimming, reading for thorough comprehension, and critical reading) and the development of language skills exercises (vocabulary, structure, and discourse). The third section of the article discusses lesson planning within a psycholinguistic framework and presents a sample lesson plan in English as a second language which emphasizes a skills approach to reading. Lessons are planned for maximum flexibility,
\end{abstract}

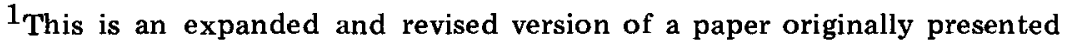
at the Ninth Annual TESOL Convention in Los Angeles, March, 1975.

${ }^{2}$ This paper was written while the authors were Research Assistants at the English Language Institute, University of Michigan. Thanks are due to $\mathrm{H}$. Douglas Brown, Acting Director, for his support of our work in materials development which resulted in Reader's Choice: A Reading Skills Textbook for Students of English as a Second Language (Baudoin, Bober, Clarke, Dobson and Silberstein, University of Michigan Press, 1977). Many of the ideas expressed in this paper were refined during the three year development of Reader's Choice; special thanks are due to our co-authors for many hours of valuable shop talk. Thanks also to Bill Black (now at Georgetown University) for comments on an earlier version of the paper. 
allowing the teacher to take advantage of students' interests and needs.

\section{THEORETICAL PREMISES}

There is no "psycholinguistic method" for teaching reading; the value of psycholinguistics lies in the insights it provides into the reading process (see, for example, Smith and Goodman 1973). In the past the reader was viewed as working through a text in a rigid, word-by-word fashion, decoding information in a precise manner from print to speech to aural comprehension. Frank Smith (1973) emphasizes two important contributions of psycholinguistics which make such an interpretation impossible.

First, it has been established that there is a severe limit to the amount of information that we are able to receive, process and remember (Miller 1967). The reader, therefore, does not use all the information on the page, but rather, must select the most productive language cues in determining the message of the writer. From this it follows that reading is necessarily a rapid process which could not proceed word by word.

Second, research has shown that reading is only incidentally visual (Kolers 1969). More information is contributed by the reader than by the print on the page. That is, readers understand what they read because they are able to take the stimulus beyond its graphic representation and assign it membership to an appropriate group of concepts already stored in their memories.

Goodman (1970) summarizes the psycholinguistic perspective of reading:

Reading is a selective process. It involves partial use of available minimal language cues selected from perceptual input on the basis of the reader's expectation. As this partial information is processed, tentative decisions are made to be confirmed, rejected or refined as reading progresses. (260)

From this paragraph, which describes the proficient native-language reader, inferences can be drawn which are important in the preparation and use of second language (L2) reading materials.

First, the definition assumes that reading is an active process. The reader forms a preliminary expectation about the material, then selects the fewest, most productive cues necessary to confirm or reject that expectation. This is a sampling process in which the reader takes advantage of his knowledge of vocabulary, syntax, discourse, and the "real world." Skill in reading, therefore, depends 
on precise coordination of a number of special skills. Providing students with practice in these skills and helping them to develop consistent "attack strategies" should be the focus of any reading program.

The second inference, closely tied to the first, is that reading must be viewed as a two-fold phenomenon involving processcomprehending-and product-comprehension. (For a discussion of this distinction see Goodman and Burke 1973.) The process of working through a reading task, with the mistakes and false starts that this involves, is often as important as producing correct responses to post facto comprehension questions. Our responsibility as reading teachers, therefore, goes beyond presenting our students with passages followed by comprehension questions. We must construct reading tasks which reward students as much for trying as for getting the correct answer.

Third, reading involves, as Goodman (1970) stated, an interaction between thought and language. The reader brings to the task a formidable amount of information and ideas, attitudes and beliefs. This knowledge, coupled with the ability to make linguistic predictions, determines the expectations the reader will develop as he reads. Skill in reading depends on the efficient interaction between linguistic knowledge and knowledge of the world. Two things follow from this. Students must have "conceptual readiness" for each task: reading activities must either hook into the students' knowledge of the world, or the teacher must fill in the gaps before the task is begun. Furthermore, this perspective underscores the importance of individualized reading tasks since it is recognized that each student brings special strengths and weaknesses to every activity.

Fourth, psycholinguistic theory emphasizes the importance of using semantically complete readings. Research shows (see, for example Menosky 1971, Goodman and Burke 1973) that reading errors change significantly as the reader progresses into a passage, supporting the position that the reader builds on a previous store of knowledge by adding information from the reading. This finding suggests that successful reading lessons depend not only on the students' efficient use of strategies and knowledge, but also on the nature of the reading passage. The easiest passage is not necessarily the shortest, but rather the one which is conceptually complete.

Following directly from this perspective, our goals as reading teachers are: (a) to train our students to determine beforehand their goals and expectations for a given reading activity; (b) to teach our students to use reading strategies appropriate to the task 
at hand; (c) to encourage our students to take risks, to guess, to ignore their impulses to always be correct; and (d) to give our students practice and encouragement in using the minimum number of syntactic/semantic clues to obtain the maximum amount of information when reading.

In the confusion of preparing and presenting lessons to large, heterogeneous classes, it seems almost impossible to adhere to a productive theoretical framework. How do we build bridges between theory and practice? How do we introduce our students to effective reading strategies? How do we teach the group while assisting individuals? Most importantly, how do we build bridges between the classroom and the real world; how do we develop an independence in our students that allows them to leave our classrooms with a modus operandi which serves them well in new and more challenging environments? These issues are examined in the next section.

\section{ACHIEVING GOALS}

\section{Learning Environment}

Our ultimate goal is to foster independence in our students. An independent student not only uses various skills and strategies on cue, but is able to determine for himself his predictions for a reading, his goals, and appropriate reading strategies. The following learning environment encourages such independence.

We advocate a learning environment that involves all individuals - teachers as well as students-in a cooperative process of setting and achieving goals. Classroom activities should parallel the "real world" as closely as possible. Since language is a tool of communication, methods and materials should concentrate on the message, not the medium. In addition, the purposes of reading should be the same in class as they are in real life: 1) to obtain a specific fact, or piece of information (scanning), 2) to obtain the general idea of the author (skimming), 3) to obtain a comprehensive understanding of a reading, as in reading a textbook (thorough comprehension), or 4) to evaluate information in order to determine where it fits into one's own system of beliefs (critical reading). Our students should become as conscious as we are of the purpose for reading, so that they will be able to determine the proper approaches to a reading task. 


\section{Role of Teacher}

Following the admonitions of Earl Stevick (for example $1973 a, b, 1974 a, b, 1975$ ), we utilize a paradigm of L2 classroom activity which minimizes teacher intervention, forcing the students to use and develop their new language skills. Within this paradigm we see three roles for the teacher: the teacher as teacher, the teacher as participant, and the teacher as facilitator.

The teacher as teacher is necessary only when the class is attempting to resolve a language problem, for it is only in this situation that the teacher is automatically presumed to possess more knowledge than the students. This role can be minimized if the students' attack strategies and reading skills have been effectively developed. If the task is realistic, and if the students have learned to adjust their reading strategies according to the task, there should be little need for teacher intervention.

The teacher is a participant in activities in which the knowledge and opinions of all persons in the class are of equal weight. Such activities would include discussions arising from reading activities, forming judgments about ideas encountered in readings, and activities which emphasize learning about a subject through the medium of the L2.

The teacher is a facilitator when creating an environment in which learning can take place, where linguistic expertise is required only in the event of communication breakdown. Often assignments can be discussed and corrected without teacher participation. Individualized assignments or small group sessions also require little direct teacher intervention.

This paradigm of the L2 classroom has two important advantages. First, it puts teachers in their place, emphasizing the individuality of students and reducing the compulsion we sometimes feel to control classroom activity. This relieves us of feelings of guilt and frustration occasioned by unsuccessful attempts at coercing the students to keep together. Second, it puts the responsibility for learning squarely on the shoulders of the students, which is where it belongs.

Materials

The problem of materials is one faced by all teachers. While it may be true that a good teacher can make almost any set of reading materials work in class, it is obvious that properly con- 
ceived reading exercises free the teacher to work more efficiently with students to solve individual reading problems. As reading teachers we generally find ourselves in one of two situations: either we are trying to adapt a textbook to suit our needs, or we are trying to find readings and write our own exercises to fill gaps in our curriculum. The following sections discuss the evaluation, preparation and use of materials in the L2 reading class.

Evaluating Reading Selections. Whether we are looking for readings from the "real world" or deciding which selection to use from an assigned text, there are two factors that need to be considered before a reading is taken into the classroom.

Is the reading selection appropriate to both the proficiency level and the interest of the students? Both aspects of a reading, linguistic difficulty and semantic relevance, should be weighed before it is selected for use. There is evidence to suggest that relevance is a more important criterion than difficulty in selecting readings (Niles 1970). A student with the requisite amount of knowledge and interest in a subject is more likely to force himself through a difficult passage than through a relatively easy selection in which he has no interest.

Can the selection be made to provide practice in the skills which you need to reinforce? Given the demands of day-to-day teaching it is easy to fall into the trap of using a particular type of exercise because it is easy and enjoyable. It is at this point, however, that we need to shift to a different type of task since ease of execution is one indication that students have mastered a particular skill. It is also important from the viewpoint of classroom dynamics to vary the focus of skill work in a realistic way, thereby emphasizing the fact that outside the classroom reading goals and tasks vary greatly from one type of material to the next. It is also true that a single reading might provide practice in a number of skills. A menu, for example, is usually scanned, but skimming for a general idea of the type of restaurant, and the range of prices, is also realistic. Poetry is often used in reading classes only to increase students' literary appreciation, but it is an excellent vehicle for working on vocabulary-from-context skills, getting the main idea, or drawing inferences. An essay might be skimmed initially to determine the author's attitude toward an issue, followed by careful then critical reading to determine such things as who the intended audience is, if the author's presuppositions are valid, and ultimately whether or not the reader agrees with the author. 
By varying the tasks students are expected to perform, we not only make classes interesting, but also show students that skills can be used with a wide range of materials and that the same reading might profitably be attacked several ways.

Preparing and Using Materials. Once we have decided to use a reading passage, we need to make a number of decisions concerning the tasks we ask our students to perform with the selection. First, the selection determines what we try to do with it. If we want students to practice determining the main idea of a passage, we must find readings which are well-organized with topic sentences and supporting details. If a selection contains many facts and figures, it would probably work well in a scanning exercise. We should not force students to perform an unrealistic task with a reading merely because we have determined that it is time to work on a particular skill. If we want to work on skimming, for example, it is our responsibility to search until we find an appropriate reading.

Next, we must be careful to teach, then test. A common problem with reading texts is the tendency to ask students to produce a vocabulary item or to exhibit proficiency with a skill before they have been given adequate exposure and practice. Whether we are writing our own materials or adapting textbooks, we must make a consistent effort to introduce, model, reinforce, and review new learning tasks before we expect students to perform on their own. A good rule of thumb is to initially evaluate all exercises to determine exactly what is being required of the students, then to mentally review previous learning activities to make sure students can reasonably be expected to perform that task. Many cloze-type tests which pass for vocabulary review exercises actually require a firm grasp of syntax skills which may not have been explicitly taught. Students' failure to do well on such exercises may indicate weaknesses in knowledge of the structure of the L2, not in knowledge of vocabulary. In addition, cloze exercises require productive knowledge of vocabulary while students may not yet have been provided with the opportunity to develop productive control of these items.

Third, exercises should be written and used to provide maximum individualization. Reading involves an interaction between thought and language, a point of view which places great importance on the information and experiences that each reader brings to a task. Furthermore, we can assume that no two human beings learn languages at the same rate or in quite the same way. 
These two facts offer a strong case for individualizing instruction; while it is clearly impossible to prepare a separate lesson for each student, there are a number of things we can do to increase the individualization of our teaching. By producing a large number of exercises arranged hierarchically according to difficulty or by adding to the number of exercises or exercise items already in a text, we make it possible for each student to do as much as he is able to do. This gives all students ample practice. In addition, class time can be arranged so as to give teachers the opportunity to work with individuals and small groups. Of course, it may sometimes be necessary to find or produce exercises for individuals, to assign extra work to faster students or remedial work to slower students.

Finally, it is important that we develop flexibility in sequencing the use of exercises which accompany a reading. Typically, textbook exercises follow the reading selection. However, students can benefit by working with selected vocabulary and comprehension activities as well as discussion/composition topics before they begin to read. Students are more likely to experience success with a reading if they are familiar with selected vocabulary items before they begin reading. Likewise, attempting to answer comprehension questions before reading challenges students to read a passage to confirm or refute their guesses. If discussion/ composition questions are discussed before the selection is read, students are given the opportunity to think the issues through in advance and thus are able to read far more critically.

Working through exercises before students attack a reading can be the single most effective tool in getting them to take the risk and read to the end. As long as we maintain a sound theoretical perspective of the work we ask our students to do, we should not feel obligated to follow the "accepted" textbook sequences of: reading, comprehension questions, vocabulary, discussion, and composition.

Developing Reading and Language Skills. At the intermediate and advanced levels we can assume that students possess a basic competence in English and that our primary task is to teach reading. Reading is, however, a language process, and reading teachers are inextricably bound up in the teaching of the second language itself. Although in practice is is impossible to separate reading instruction from general language instruction, for the purposes of discussion it is convenient to consider materials development as being composed of two tasks: the development of 
reading skill exercises (scanning, skimming, reading for thorough comprehension, and critical reading) and the development of language skill exercises (vocabulary, structure, discourse), both of which enable students to read more efficiently by using a minimum number of linguistic clues to obtain maximum information. First let us turn our attention to reading skills.

Reading skills. Skimming is quick reading for the general drift of a passage. It is an activity which is appropriate when there is not time to read something carefully or when trying to decide if careful reading is merited. It is reading with a general question in mind: "Does this book treat generative semantics or merely transformational grammar?" or "Is this author for or against capital punishment?" Since we assume that students skim in their own languages, we see our task as helping them to transfer this skill to English. Although tips such as "Take advantage of chapter titles and subheadings," "Read first and last sentences in the paragraphs," and "Let your eyes travel quickly, catching adjectives and adverbs" are useful, the only way to improve this skill is to be forced to read more and more rapidly and to formulate appropriate questions before beginning. At first we must provide the skimming questions and coach students through passages; later students are expected to form appropriate questions and predictions and to push themselves to read quickly. (Many times textbook comprehension questions are general enough to be good pre-reading skimming questions.)

Scanning is similar to skimming in that the reader is pushing himself through a selection at an initially uncomfortable rate, but the search is more focused since the information needed is very specific-usually a date, a number, or a place. Before scanning the reader forms preliminary questions such as: "When will the candidates debate the tax reform bill?" or "What was the final score of the rugby match?" In addition to teaching students to take advantage of textual clues, as they do in skimming, we should also make them aware of the graphic form the answer is likely to take: written number, numeral, capitalized word, or short phrase containing key words. As in skimming, students gradually become less dependent on our cues until they become self-sufficient. It is important to use selections which can be realistically scanned (that is, those containing specific information) and selections which are commonly scanned in "real life": for example, the sports page, menus, classified ads, and telephone books. (Many textbook questions meant for general comprehension are good scanning questions because they focus on minute points.) 
Reading for thorough comprehension is reading in order to master the total message of the writer, both main points and supporting details. It is that stage of understanding at which the reader is able to paraphrase the author's ideas but has not yet made a critical evaluation of those ideas. This type of reading is the primary concern of most reading classes. In fact, the most common weakness of reading courses is that this style of readingthe careful word-by-word approach-is practiced exclusively, without recognition of the fact that it is not necessary for some tasks and insufficient for others. Of course, holding students accountable for what they have read is valid. However, when developing thorough comprehension questions, a number of pitfalls should be avoided. We must make sure the questions reflect the focus and direction of a passage and that the information demanded by a question is accessible to the students during a careful reading. A good rule of thumb to follow when developing exercises is to read the passage and construct initial questions on the major points without looking back to the selection; we can hardly expect students to retain more after one reading than we have. Certain materials (such as research articles or textbooks) require careful reading and study, and we should expose students to a number of such readings. We do so, however, only after we are confident that they understand the situations in which such study is warranted.

Finally, critical reading requires us to push our students beyond the "thorough comprehension" stage of reading, to encourage them to react to readings with the same critical judgement they probably exercise when reading in their native languages. This critical reading ability is often suspended when students undertake reading tasks in a second language, perhaps because they feel a great sense of accomplishment merely at having deciphered the author's message. In order to build critical reading skills, we need to find readings which argue a point of view or which presume certain attitudes on the part of the readers. Examples of critical reading questions are: "For what purpose and for what audience is this intended?" "What knowledge and attitudes does the author presume of the audience?" "Are you convinced by the evidence presented by the author to support the claims made?" "Does your own experience support the conclusions reached by the author?" and "Do you share the author's point of view?" Such questions open up for students a completely new perspective of the selection, and lead to discussion in which they must use vocabulary and information from the passage to support 
their opinions. Many ESL reading texts for example, are guilty of hindering students' critical reading skills by taking the author's credentials for granted, by not asking students to critically evaluate the issues. (Critical reading demands a certain amount of class discussion time if students are to answer questions such as those posed above.)

Language skills. Our students' efficiency in using reading skills is directly dependent upon their overall language proficiency-their general language skills. In addition to presenting exercises such as those mentioned above, we must also systematically treat specific language problems in the mode of reading. There are three areas of language skills work on which we focus: vocabulary, syntax, and discourse. At this point we turn specifically to English as the target language for consideration.

Vocabulary work is the easiest to devise and the easiest to abuse. Virtually all texts in English as a second language (ESL) work with vocabulary items, but it takes a teacher with a strong theoretical commitment to use such exercises effectively. A basic premise which should not be violated is: work with real language contexts. Words are vehicles of meaning and as such rarely occur in isolation. Three types of vocabulary attack strategies emphasized are: obtaining meaning from context, from morphological analysis, and from monolingual English dictionaries.

Guessing vocabulary from context is perhaps the most important of the vocabulary attack skills. Students must be made aware of the number of language clues available to them when they are stopped by an unfamiliar word. They should realize that they can usually continue reading and obtain a general understanding of the item. In context work, there are syntactic and semantic parameters of which we should make our students aware. We can emphasize the redundancy of language by demonstrating the types of contexts which can provide the meaning of an unfamiliar word:

synonym in apposition: Our uncle was a nomad, an incurable wanderer who never could stay in one place.

antonym: While the aunt loved Marty deeply, she absolutely despised his twin brother Smarty.

cause and effect: By surrounding the protesters with armed policemen, and by arresting the leaders of the movement, the rebellion was effectively quashed.

association between an object and its purpose or use: The scientist removed the treatise from the shelf and began to read.

description: Tom received a new roadster for his birthday. It is a sports model, red with white interior and bucket seats, capable of reaching speeds of more than $150 \mathrm{mph}$. 
example: Mary can be quite gauche; yesterday she blew her nose on the new linen tablecloth.

Without burdening the student with linguistic jargon we can teach students to recognize the punctuation, syntax, and discourse clues which operate in each of the above examples. Most importantly, they must be taught to recognize situations in which the meaning of a word or phrase is not essential for adequate comprehension of the passage.

If context does not provide the meaning of an unfamiliar word, morphological analysis will often provide a clue. Many ESL texts provide lists of stems and affixes with accompanying exercises. These can be used to systematically introduce the most common stems and affixes. In subsequent reading tasks, students' familiarity with morphological items can be increased by continued practice in deciphering unfamiliar words.

Finally, if all else fails and if students feel they cannot continue without knowing the meaning of a word, the dictionary can be used. Students require a systematic introduction to dictionary work if they are to become efficient dictionary users. Practice in scanning for words, and in the use of syntactic and semantic clues to select the proper definition for a given context should be provided.

In using ESL reading textbooks, we become more effective if we are aware of a number of common weaknesses of the vocabulary exercises. Often the rationale for choosing the words to be glossed seems arbitrary; one doesn't know if the words are glossed because they are difficult or because they are useful. It is often unclear if students are expected to make these items part of their active vocabularies. What vocabulary "teaching" there is consists of lists of words in isolation or with definitions. Neither format successfully teaches vocabulary. Many vocabulary exercises test without any teaching and are often unrealistic in two ways. Either the task itself is unrealistic ("Form a sentence with the word dilemma") or the presumed ability to do the task is unrealistic (asking students to produce vocabulary of which they have only a receptive command).

In such cases it is up to the teacher to determine how much vocabulary building should take place and then to provide contexts in which words can be introduced and subsequently reinforced. Introducing unfamiliar vocabulary in several sentences, each providing a clear context, has proved to be successful. (Of course prereading vocabulary work should be restricted to only those items whose meaning is not accessible from the passage.) Assuring 
that vocabulary items appear again and again in comprehension and discussion activities serves as reinforcement. If a word appears in a technical context in a reading but would be of use to students in more generalized contexts, the teacher should provide such contexts for the learner. This can be done orally or in writing. Items which do not impede communication of the author's ideas and which will not prove useful later should be ignored. Items which impede understanding, but which are rarely used in English should be quickly glossed by the teacher and then ignored.

Syntax work in reading classes is conducted on a diagnostic basis: only when a syntactic structure causes a communication breakdown do we work with it. When encountered in a reading, structure problems should be pulled out and explained. If a particular structure persists in causing comprehension difficulties or if the whole class is troubled by it, relevant exercises from grammar texts or teacher-constructed drills should be presented for intensive work. It is important, however, to emphasize grammar work as a tool for improving reading skills and to constantly reinforce the tactic of analyzing difficult prose for recognizable grammatical elements. Likewise, grammar exercises in reading texts should be analyzed to determine if the syntactic elements studied actually cause reading problems. If they do, the teacher should make explicit their value to the students and should build the necessary bridges between the exercises and the reading. If the exercises treat grammar points which do not give our students trouble when they read, we should not hesitate to skip the exercises en tirely.

Discourse analysis consists of making students conscious of the effect of organization on the message of a writer. Rough outlining can be of value in showing students how one idea leads to the next. Many times this kind of work can be tied into the students' writing classes, where they may be working with such organizational schemes as comparison and contrast, generalization and specifics, and chronological order. ESL students should be made aware of the strong tendency in English for linear argumentation. Unlike many other languages, contiguous English sentences often imply causation or chronological sequence of events. Therefore, it is necessary to emphasize the arrangement of ideas as an important clue in deciphering the overall meaning of a text. We must also take pains to point out the styles which generally accompany certain types of writing. Discourse work lacks the rigor of vocabulary and syntax because the system of organizing largerthan-sentence language units is not rigid and because writers are 
not always as careful in organizing their ideas as they are in checking their grammar and word usage. Although discourse work cannot be reduced to formulas as easily as our vocabulary and syntax lessons, it is nevertheless imperative to help students develop an awareness of the conceptual presuppositions that native-speaker writers and readers apply to the organization of a text. In addition to increasing the ability to make predictions based on syntax and semantics, students should be developing an ability to predict content on the basis of textual organization.

\section{SAMPLE LESSON PLAN}

In the preceding pages we have attempted to show how a psycholinguistic perspective of reading might affect the learning environment, teacher behavior, and the preparation of $L 2$ reading materials. We will narrow the focus now to describe a week's sequence of events in an intermediate or advanced ESL reading class (see Sample Lesson Plan).

A few general comments apply to all lesson plan preparation. First, although lessons are planned painstakingly, we must also allow for maximum flexibility. On the one hand, we should plan carefully, establishing loose time limits for each task. On the other hand, it is assumed that teachers will take advantage of any situation which may arise, abandoning prepared tasks for activities which spark student interest. This does not mean that reinforcement in a particular skill will be forfeited; our constant efforts to systematically reinforce and recycle all skills work throughout the semester allow us flexibility on a day-to-day basis. Approximate time limits are established in advance for each activity so that the teacher realizes, for example, that a successful activity is being continued at the expense of another. This type of flexibility in the classroom-spontaneously extending the time allotted for one activity so that not enough time remains for a second planned activity -may leave teachers with time on their hands at the end of the hour. In an effort to avoid this problem more than enough work is planned for each day. If we have extra exercises ready to use, we are less likely to push forward with a task which is boring, too difficult, or too long.

Second, while we acknowledge the value of such non-reading activities as discussion, writing, and focused grammar or vocabulary work, we are committed to the view that one learns by doing: in a reading class, students should read. Furthermore, as much as possible, students should work with conceptually complete reading 
tasks. Focused work on words, sentences and paragraphs is tolerated because a teacher can thereby deal more effectively with specific language problems which have caused comprehension difficulties in longer readings.

Finally, because our ultimate goal is to make students independent of our guidance, we should allow for consistently greater student participation in determining the appropriate strategies for particular readings. As the semester progresses, it is hoped that the class will gradually develop into a group of people working together to increase their reading skills.

A few comments are necessary conceming the lesson plan presented here. The activities outlined would be appropriate for intermediate or advanced students who have worked together for several weeks. This is important for two reasons. First, we hope that a non-threatening atmosphere has been established in which people feel free to volunteer opinions and make guesses without fear of ridicule or censure. Second, we can assume that by now students recognize the importance of a skills-based reading program and that they are working with the teacher to improve those skills using a variety of readings and exercises. That is, they have been introduced to all of the skill exercise types and are working toward that ultimate goal of complete independence.

The lesson plan is meant only as an example of how goals might be translated into practice. We do not imply that a particular presentation is the only one possible for a given reading activity nor that the exercises presented here are the only activities possible to achieve our goals.

These lessons, planned for 50-minute, ESL reading classes, are ambitious; we have chosen to provide more than enough work in the belief that it is better to err in the direction of too much rather than too little. Approximate time limits for each activity are indicated. Below each exercise heading appear possible sources of materials and a brief description of how the exercise type might be used.

A close examination of the sample lesson plan reveals several important characteristics to be found in any successful teaching situation. First, and most importantly, the plan represents a skills approach to the teaching of ESL reading. The students do more than merely read passages and answer questions; the type of reading that the students are asked to perform varies from task to task. They scan the train schedule and newspaper, skim the longer reading and read it and several other selections carefully. The 


\section{SAMPLE FIVE-DAY LESSON PLAN}

\section{Day 1}

Non-prose reading (15 $\mathrm{min}$ ) (train schedule, menu, map, graph, etc.)

- Students are given teacher-prepared questions and told to scan to find the answers.

-The questions should reflect "real life" situations.

- The work is fast-paced and oral, students working individually or in small groups.

Paragraph work (20 min) (paragraphs from Baudoin, et al., Harris, SRA, or teacher-prepared)

-As an introduction, a paragraph is read by the teacher, and the students are given time to answer the questions. Discussion follows, with students defending answers using vocabulary and syntax analysis. Students are then given the opportunity to work individually.

- Students read silently and answer questions.

-Discussion follows with the class as a whole, in small groups, or in pairs. Intensive work is done on determining the main idea, drawing inferences, as well as sentence and discourse work.

-If students aren't able to finish in the allotted time or if problems arise, the work can be continued as homework.

Introduction to longer reading (15 $\mathrm{min}$ ) (ESL textbook reading of over 2000 words found, for example, in Baudoin et al., and Baumwoll and Saitz)

-Reading is introduced by a discussion relating the topic to students' experiences, followed by an introduction of potentially difficult vocabulary from the reading.

-The teacher reads the first few paragraphs orally to introduce the students to the reading. Discussion follows on the topic and on potential vocabulary and syntax problems.

-If time permits, students skim the selection to answer general questions posed by the teacher.

Assignment

- Read longer reading, answer comprehension questions for Day 3.

-Finish paragraph work, if necessary.

Day 2

Paragraph work (10 $\mathrm{min})$

-Finish paragraph work begun on Day 1.

Vocabulary work (15 min) (vocabulary from context, stem/affix, or dictionary: exercises taken from Baudoin et al., Harris, Yorkey, or other skills textbook or are teacher-prepared)

-Intensive oral skill work in which students are pushed at fast pace. Focus is on skills not on learning new vocabulary.

- Teacher-prepared exercises can be used to introduce vocabulary from the next reading selection.

Short passage $(25 \mathrm{~min}$ ) (ESL textbook such as Baudoin et al., Saitz and Carr, Hirasawa and Markstein, or teacher-prepared activity; reading of 500-1000 words;

-Students do intensive forced reading for a particular purpose. (The reading determines what you do with it.)

-The teacher: a) reads the passage orally to the students while they read silently forcing them to read quickly, or b) sets a time limit for silent reading.

-The reading is followed by comprehension questions to be done orally, or in writing if true/false, multiple choice format is used.

-Discussion of questions can take place with the class as a whole, in small groups or in pairs.

Assignment

- Reminder from Day 1 to read longer reading and answer comprehension questions.

Day 3

Longer reading ( $50 \mathrm{~min}$ )

-Vocabulary exercises are answered orally and quickly. 
-Comprehension questions are discussed, flipping back and forth from questions to passage to scan for answers when difficulties arise. This can be done by the class as a whole, in small groups or in pairs.

-Teacher pulls out sentences and vocabulary items for explanation and discussion as problems arise. Care is taken to build bridges between this and previous syntax and vocabulary skill work.

-The passage is discussed using text and teacher-prepared questions.

-Teacher can act as facilitator: keeping discussion moving, encouraging all students to contribute, or small groups can elect a chairperson from among the students. Discussion focuses on evaluations arising from critical reading.

- Teacher moves students through a variety of activities so that, although the content is the same for fifty minutes, the pace and focus keep everyone interested in the work. Assignment

-Vocabulary review exercises or possibly a composition based on the reading passage. The assignment should allow students to capitalize on vocabulary and syntax work which accompanied the lesson.

Day 4

-Go over homework.

Structure work (15 $\mathrm{min}$ ) (worksheets from Quirk and Greenbaum, Rutherford, Praninskas, or teacher-prepared).

-Work should be done orally or, if in writing, in a workshop setting where the teacher moves from student to student. Discussion occurs with class as a whole, in small groups, or in pairs.

- Teacher can provide work on structures which have caused reading comprehension problems in previous reading. This might include work on problems uncovered in Wednesday's work.

- Extra work can be assigned as homework as needed.

Short passage $(20 \mathrm{~min}$ ) (ESL textbook or teacher-prepared reading of approximately 500 words with comprehension, vocabulary, and syntax exercises as appropriate)

- Reading can be on a topic seen earlier, or a new content area can be introduced.

-Students can be asked to determine the proper goals and strategies for the task. A time limit is agreed upon.

-The passage is read and exercises are completed in class.

-Discussion follows reading, guided by comprehension questions.

Realia (15 min)

-Discussion of current news which students are likely to know about from TV or radio, and which the teacher can predict will appear in newspapers daily.

-Teacher and students discuss topic; the teacher provides cultural, vocabulary information, as needed.

Assignment

-Buy the same English language newspaper that evening and scan to find all articles on "realia" topic. Read the articles. Answer teacher-prepared questions the preparation of which requires only a general knowledge of the kinds of information available daily on the "realia" topic e.g., "Who is Mr. X?" "What arguments are used by opponents of the proposed project?" Bring newspaper to class on Day 5.

Day 5

Realia (35 min)

-Students discuss the articles which treat Thursday's "realia" topic. Teacher will have read the articles and prepared appropriate exercises.

-Students do intensive oral work with the newspaper. Tasks are realistic: comparison shopping with classified ads, analysis of news reports, etc. Work can be done as a class, in small groups, or in pairs.

Poetry (15 $\mathrm{min})$ (teacher-prepared exercises)

-This kind of activity is done for a change of pace. Teacher should emphasize that poetry requires the same skills as other reading selections.

- Poetry is especially good for reinforcing vocabulary from context skills, using syntax clues and for drawing inferences. 
vocabulary and syntax work is presented as a tool for comprehension, appropriate for helping students solve persistent reading problems.

Second, within a single week a great variety of activities is presented. In the course of any single lesson the tempo and task change several times. Monday, for example, begins with a scanning exercise, followed by paragraph work, concluding with a vocabulary and skimming introduction to the longer reading which will not be due until Wednesday. In the course of the week, virtually all language and reading skills are reinforced in a variety of contexts and with a variety of materials.

Of course, the classroom dynamics change to fit the task. The train schedule and poem are treated as a class activity, the teacher encouraging students to volunteer answers and opinions. The paragraph work on Monday, as well as the vocabulary and structure exercises on Tuesday and Thursday, might be organized as workshop sessions, giving students the chance to work at their own pace and providing the teacher with the opportunity to assist individuals. For such lessons it is necessary to provide either a great number of exercise items or several worksheets, so that faster students are challenged either by the quantity or difficulty of the material. We have had great success having students discuss reading comprehension questions in small groups. Students choose a chairperson who is responsible for seeing that everyone talks, that all comprehension problems are resolved, and that consensus is reached on each exercise item. Students are forced to defend their choices with portions of the text. This process encourages student autonomy and responsibility and minimizes teacher intervention.

The role of the teacher also changes from activity to activity. During vocabulary and structure work, the teacher is a teacher, providing help and encouragement as students work to solve language problems. The teacher is a facilitator during the poetry and short passage readings, intervening only in the event that linguistic expertise is needed to keep discussion going. In the analysis of news events and discussions of how readings relate to the "real world," the teacher is primarily a participant on equal terms with the students in exploring a mutually interesting topic. Of course, the role and behavior of the teacher can change a number of times in the course of one session to suit the situation. It is hoped, however, that, as the semester progresses, the teacher as teacher will gradually be replaced by the teacher as facilitator and participant. 
A third important feature of this lesson plan is the opportunity to encourage students to choose their own reading strategies and to apply the skills dictated by the strategy chosen. It should be noted that the longer reading is introduced by the teacher through vocabulary work and discussion, followed by skimming. It is often the case that students are discouraged by long readings and should therefore be given as much of this kind of support as necessary in attacking a long selection. It is hoped that the procedure used by the teacher will be repeated by the student when similar readings are attacked in the future. Later in the week, students are encouraged to choose their own strategies for attacking Thursday's short selection and to be able to defend their approaches. Often the teacher will want to simulate a "real life" situation, give the students a task, and ask them how they would approach it. One's approach to a newspaper editorial, for example, might be quite different depending on whether one is reading the selection for pleasure or for a university political science course.

Throughout the semester, students are taught to shift gears, to vary their reading strategies according to their goals for the selection at hand. As they become more proficient readers, we expect them to determine for themselves what they read, why they read it, and how they read it.

\section{REFERENCES}

Baudoin, E. M., Bober, E. S., Clarke, M. A., Dobson, B. K. and Silberstein, S. 1977. Reader's Choice: A Reading Skills Textbook for Students of English as a Second Language. Ann Arbor: University of Michigan Press.

Baumwoll, D. and Saitz, R, L. 1965. Advanced Reading and Writing. New York: Holt, Rinehart and Winston.

Goodman, K. S. 1970. Reading: a psycholinguistic guessing game. In H. Singer and R. B. Ruddell (eds.), Theoretical Models and Processes of Reading, 259-271. Newark, Del.: International Reading Association.

Goodman, K. S. and Burke, C. 1973. Theoretically Based Studies of Patterns of Miscues in Oral Reading Performance. U. S. Department of Health, Education and Welfare, Office of Education.

Harris, D. P. 1966. Reading Improvement Exercises for Students of English as a Second Language. New Jersey: Prentice-Hall Inc.

Hirasawa, L. and Markstein, L. 1974. Developing Reading Skills: Advanced. Rowley, Mass.: Newbury House Publishers, Inc.

Kolers, P. A. 1969. Reading is only incidentally visual. In K. S. Goodman and J. T. Fleming (eds.), Psycholinguistics and the Teaching of Reading, 8-16. Newark, Del.: International Reading Association.

Menosky, D. M. 1971. A psycholinguistic description of oral reading miscues generated during the reading of varying portions of text by selected readers from grades two, four, six and eight. Unpublished doctoral dissertation. Wayne State University. 
Miller, G. A. 1967. The magical number seven, plus or minus two: some limits on our capacity for processing information. In G. A. Miller, The Psychology of Communication, 14-43. New York: Basic Books.

Niles, O. S. 1970. School programs: the necessary conditions. In K. S. Goodman and O. S. Niles (eds), Reading: Process and Program, 41-74. Urbana, Ill.: National Council of Teachers of English.

Praninskas, J. 1975. Rapid Review of English Grammar, (2nd ed.). Englewood Cliffs, New Jersey: Prentice-Hall, Inc.

Quirk, R. and Greenbaum, S. 1973. A Concise Grammar of Contemporary English. New York: Harcourt, Brace Jovanovich, Inc.

Rutherford, W. E. 1968. Modern English. New York: Harcourt, Brace and World. Revised 1974.

Saitz, R. L. and Carr, D. 1972. Selected Readings in English. Cambridge, Mass.: Winthrop Publishers, Inc.

Smith, F. (ed.). 1973. Psycholinguistics and Reading. New York: Holt, Rinehart and Winston.

Smith, F. and Goodman, K. S. 1973. On the psycholinguistic method of teaching reading. In F. Smith (ed.), Psycholinguistics and Reading, 177-182. New York: Holt, Rinehart and Winston.

Science Research Associates. 1965. Rate and Power Builders. Chicago, Illinois.

Stevick, E. W. 1973a. Review of Curran's counseling-learning: A whole person model for education. Language Learning 23.259-271.

Stevick, E. W. 1973b. Before linguistics and beneath method. In Georgetown University Roundtable, 99-106. Washington, D. C.: Georgetown University Press.

Stevick, E. W. 1974a. Language teaching must do an about face. Modern Language Journal 58.379-383.

Stevick, E. W. 1974b. Review of Gattegno's Teaching Foreign Languages in the Schools: The Silent Way. TESOL Quarterly 8.305-314.

Stevick, E. W. 1975. One simple visual aid: a psychodynamic view. Language Learning 25.63-72.

Yorkey, R. C. 1970. Study Skills for Students of English as a Second Language. New York: McGraw Hill Book Co. 